2. Ando, T., Rasmussen, K., Nyhan, W. L., Donnell, G. N., and Barnes, N. D. Propionic acidemia in patients with ketotic hyperglycinemia. J. Pediat., 78: 827 (1971).

3. Brandt, N. J., Brandt, S., Rasmussen, K., and Sch $\phi$ nheyder, F.: Hyperglycericacidaemia with hyperglycinaemia: A new inborn error of metabolism. Brit. Med. J., IV: 344 (1974)

4. Brandt, N. J., Rasmussen, K., Brandt, S., K $\phi$ lvraa, S., and Sch $\phi$ nheyder, F.: D-Glyceric acidaemia and non-ketotic hyperglycinaemia. Acta Paediat. Scand., 65: 17 (1976).

5. Chalmers, R. A., Lawson, A. M., and Watts, R. W. E.: Studies on the urinary acidic metabolites excreted by patients with $\beta$-methylcrotonylglycinuria, propionic acidemia and methylmalonic acidemia, using gas-liquid chromatography and mass spectrometry. Clin. Chim. Acta, 52: 43 (1974).

6. Cheung, G. P., Cotropia, J. P., and Sallach, H. J.: The effects of dietary protein on the hepatic enzymes of serine metabolism in the rabbit. Arch. Biochem. Biophys., 129 (1969).

7. Childs, B., Nyhan, W. L., Borden, M., Bard, L., and Cooke, R. E.: Idiopathic hyperglycinemia and hyperglycinuria, a new disorder of amino acid metabolism. Pediatrics, 27: 522 (1961)

8. Cohn, J., Wang, P., Hauge, M., Henningsen, K., Jensen, B., and Svejgaard, A.: Amylo-1,6-glucocidase deficiency (glycogenosis type III) in the Faroe Islands. Hum. Hered., 25: 115 (1975).

9. Craig, J. C., and Roy, S. K.: Optical rotatory dispersion and absolute configuration. IV. Tetrahedron, 21: 1847 (1965).

10. Dalgliesh, C. E., Horning, E. C., Horning, M. G., Knox, K. L., and Yarger, K.: A gas-liquid-chromatographic procedure for separating a wide range of metabolites in urine or tissue extracts. Biochem. J., 101: 792 (1966).

11. Dawkins, P. D., and Dickens, F.: The oxidation of D- and L-glycerate by rat liver. Biochem. J., 94: 353 (1965)

12. Fallon, H. J., and Burne, W. L.: 2-Phosphoglyceric acid phosphatase: Identification and properties of the beef-liver enzyme. Biochim. Biophys. Acta, 105: 43 (1965)

13. Fallon, H. J., Hackney, E. J., and Byrne, W. L.: Serine biosynthesis in rat liver. J. Biol. Chem., 241: 4157 (1966).

14. Fallon, H. J., and Byrne, W. L.: Depression of enzyme activity by cortisone: An effect on serine metabolism. Endocrinology, 80: 847 (1967).

15. Lancaster, G. A.: Measurement of keto- and hydroxy-acids. Application of gas chromatography-mass spectrometry to the investigation of human disease. Proceedings of a Workshop, Montreal, 1973

16. Nyhan, W. L.: Propionic acidemia and the ketotic hyperglycinemia syndrome. In: W. L. Nyhan: Heriditable Disorders of Amino Acid Metabolism, p. 37 (John Wiley and Sons, New York, 1974).

17. Nyhan, W. L.: Non-ketotic hyperglycinemia. In: W. L. Nyhan: Heriditable Disorders of Amino Acid Metabolism, p. 309 (John Wiley and Sons, New York, 1974).

18. Nynan, W. L., Borden, M., and Childs, B.: Idiopathic hyperglycinemia, a new disorder of amino acid metabolism. II. The concentrations of other amino acids in the plasma and their modification by the administration of leucine. Pediatrics, 27: 539 (1961).

19. Pierce, A. E.: Silylation of Organic Compounds, Chapt. 3 (Pierce Chemical Co., Rockford, Ill., 1968)

20. Rauschenbach, P., and Lamprecht, W.: Einbau von $C^{14}$-markierter glucose und fructose in Leberglycogen. Z. Physiol. Chem., 339: 277 (1964).

21. Schlenk, H., and Gellerman, J. L.: Esterification of fatty acids with diazomethane on a small scale. Anal. Chem., 32: 1412 (1960).

22. Sokal, R. R., and Rohlf, F. J.: Biometry, Chapt. 14 (W. H. Freeman and Co. 1969).

23. Wadman, S.K. Personal communication.

24. Walsh, D. A., and Sallach, H. J.: Comparative studies on the pathway for serine biosynthesis in animal tissue. J. Biol. Chem., 241: 4068 (1966).

25. Williams, H. E., and Smith, L. H.: The identification and determination of glyceric acid in human urine. J. Lab. Clin. Med., 71: 495 (1968)

26. Williams, H. E., and Smith, L. H.: L-glyceric aciduria, a new genetic variant of primary hyperoxaluria. New Engl. J. Med., 278: 233 (1968).

27. Sigma Chemical Co., St. Louis.

28. Pierce Chemical Co., Rockford, Ill

29. E. Merck, Darmstadt, Germany.

30. The authors wish to thank the Department of Medical Biochemistry, University of Arhus, for performing the spectropolariometric investigations.

31. This work has been supported by a grant from the Danish Medical Research Council.

32. Requests for reprints should be addressed to: S. Kфlvraa, M.D., Centrallaboratoriet, Århus kommunehospital, 8000 Århus C. (Denmark).

33. Accepted for publication May 4, 1976.

\title{
Attempts to Induce Hepatic Uridine Diphosphate Glucuronyl Transferase in Genetically Deficient Gunn Rats by Grafting of Normal Liver Tissue*
}

CORNELIS A. J. VAN HOUWELINGEN ${ }^{(10)}$ AND IRWIN M. ARIAS

Liver Research Center, Albert Einstein College of Medicine, New York, New York, USA

\section{Extract}

Liver from normal Wistar rats was grafted into the liver of homozygous Gunn rats which are deficient in UDP glucuronyl transferase (UDPGT) (bilirubin) activity. After 3 months, UDPGT activity (bilirubin) remained absent in microsomal suspensions of liver from recipient rats and no bilirubin glucuronide was detected in their bile.

\section{Speculation}

We were unable to confirm previous reports suggesting that transplantation of segments of normal rat liver into Gunn rat liver resulted in amelioration of jaundice because of UDPGT activity in the recipient liver.
Homozygous Gunn rats lack UDPGT activity with bilirubin as a substrate resulting in chronic nonhemolytic unconjugated hyperbilirubinemia (1). UDPGT activity is not enhanced in Gunn rats after treatment with phenobarbital (3).

Mukherjee and Krasner (7) transplanted small pieces of normal Wistar rat liver into the liver of Gunn rats and observed reduction in serum bilirubin concentations and virtually normal hepatic UDPGT activity (bilirubin) 3 months after the grafting procedure. Because these results have important implications for treatment of several human deficiency diseases, we repeated the experiment using similar animals and procedure. In addition, bile duct cannulation was performed in order to study the effect of liver grafting on the chemical nature of bile pigments. 
Table 1. Serum bilirubin concentrations in recipient and sham-operated Gunn rats ${ }^{1}$

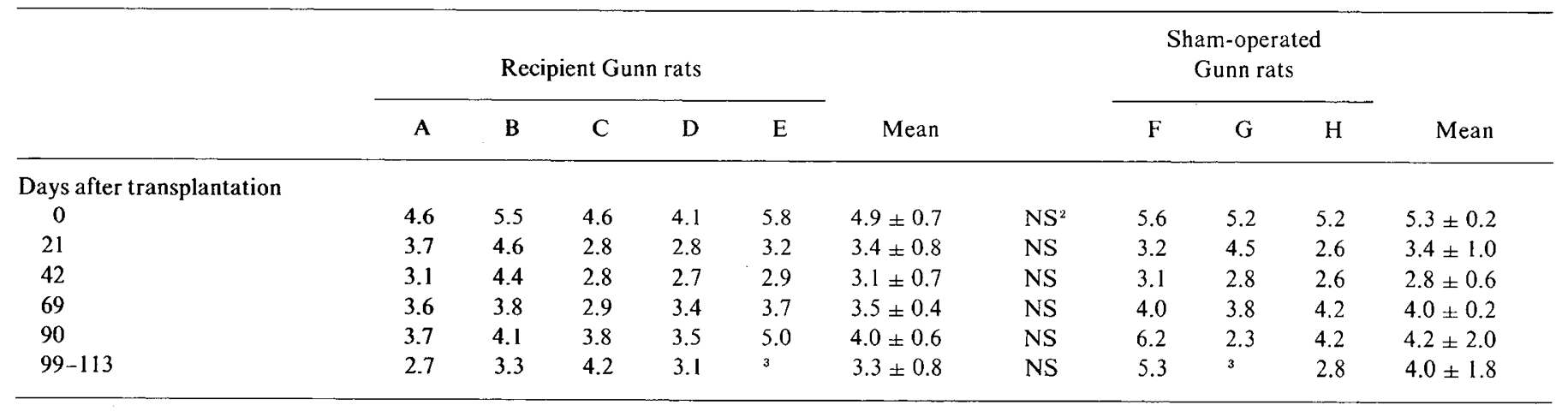

${ }^{1}$ See text for further details.

${ }^{2}$ Statistically nonsignificant difference from control at $P<0.05$.

${ }^{3}$ Death.

Table 2. Hepatic UDP glucuronyl transferase and UDP glycosyl transferase activities (bilirubin) in recipient and sham-operated GUNN rats $^{1}$

\begin{tabular}{|c|c|c|c|c|c|c|c|c|c|c|}
\hline & \multicolumn{5}{|c|}{$\begin{array}{l}\text { Recipient } \\
\text { Gunn rats }\end{array}$} & \multicolumn{4}{|c|}{$\begin{array}{c}\text { Sham-operated } \\
\text { Gunn rats }\end{array}$} & \multirow[b]{2}{*}{ Mean } \\
\hline & A & B & $\mathrm{C}$ & D & $\mathrm{E}$ & Mean & $\mathbf{F}$ & G & $\mathrm{H}$ & \\
\hline \multicolumn{11}{|l|}{ Enzyme activity } \\
\hline $\begin{array}{l}\text { UDP glucuronyl } \\
\text { transferase }\end{array}$ & 0 & 0 & 0 & 0 & 2 & 0 & 0 & 2 & 0 & 0 \\
\hline $\begin{array}{l}\text { UDP glycosyl } \\
\text { transferase }\end{array}$ & 0 & 0 & 0 & 0 & 2 & 0 & 0 & 2 & $\cdot 0$ & 0 \\
\hline
\end{tabular}

${ }^{1}$ Mean enzyme activities in normal rat liver were $320 \pm 25 \mathrm{~nm} / \mathrm{g} \cdot 20$ min and $68 \pm 9 \mathrm{~nm} / \mathrm{g} \cdot 20 \mathrm{~min}$, respectively.

${ }^{2}$ Death.

\section{MATERIALS AND METHODS}

Homozygous Gunn rats of either sex, weighing 150-250 g, were donated by Dr. Joseph Krasner, State University of New York Medical Center, Buffalo, New York. Their identity was confirmed by detection of unconjugated hyperbilirubinemia. Donor Wistar rats of either sex and of similar weight were obtained from the Animal Institute, Albert Einstein College of Medicine.

Donor Wistar rats and recipient Gunn rats were matched for sex and weight and were anaesthesized with ether. With an uterine punch biopsy forceps, a small piece of recipient liver was removed and replaced by a small piece of donor liver, identical in size. Depending on the size of the liver, three to four pieces of liver tissue were grafted in different lobes of recipient liver. The amount of transplanted liver tissue ranged from $180-250 \mathrm{mg} / \mathrm{rat}$. Three rats were sham-operated; the liver was punched in one rat and the two other rats received two pieces of liver from each other. After 3.5 months, each rat was anesthesized with $2.5-5.0 \mathrm{mg}$ Nembutal subcutaneously for $35 \mathrm{hr}$. The common bile duct was cannulated with polyethylene tubing no. 10. Rats were kept in a heated cage at $42^{\circ}$ while bile was collected on ice in the dark for $2 \mathrm{hr}$ after which the rat was killed; the liver was removed and perfused with $40-50$ cc ice-cold saline, and a biopsy of liver from the graft areas was placed in $10 \%$ formaldehyde for histologic examination. The liver was immediately frozen and stored in liquid nitrogen $\left(-180^{\circ}\right)$ for 1-3 days. When necessary, bile was also stored $-180^{\circ}$ before chromatographic study of pigments was performed.

Microsomal suspensions were prepared by differential centrifugation of liver homogenates (4) and were stored at $-15^{\circ}$ overnight or in liquid nitrogen $\left(-180^{\circ}\right)$ for $1-3$ days. Enzymatically cata- lyzed glucuronidation and glucosidation of bilirubin were studied. A digitonin-activated liver microsomal suspension, $0.2 \mathrm{ml}$, was added to $0.8 \mathrm{ml}$ Tris buffer, $0.1 \mathrm{M}, \mathrm{pH} 8.1$, containing $33 \mathrm{mM} \mathrm{MgCl}$ and $3 \mathrm{mM}$ UDP glucuronic acid (UDPGA) or UDP glucose (UDPG). Control tubes lacked UDPGA or UDPG. Microsomal suspension were activated by mixing 3:1 with digitonin suspension $(25 \mathrm{mg} / \mathrm{ml})$. The reaction was started by adding, $0.2 \mathrm{ml}$ bilirubin solution and was stopped after $20 \mathrm{~min}$. Bilirubin solution was made by dissolving $4.4 \mathrm{mg}$ bilirubin in 0.5 $\mathrm{ml} 0.05 \mathrm{M} \mathrm{NaOH}$, and diluting this solution with phosphate buffer, $\mathrm{pH} 7.8(1: 30, \mathrm{v} / \mathrm{v})$. The reaction was performed in a dark room at $37^{\circ}$ in a shaking waterbath. After incubation, the mixtures were submitted to the diazo reaction described by Van Roy and Heirwegh (8). Azo pigments were extracted with methylpropylketone- $n$-butyl acetate $(17: 3)$ and color in the extract was determined spectrophotometrically at $530 \mathrm{mM}$ (conjugated bilirubin was calculated assuming $E_{530} 44.410^{3} \mathrm{M}^{-1} \mathrm{~cm}^{-1}$ ) (8). Protein was determined by the method of Lowry et al. (5) with bovine serum albumin as reference. Bilirubin in bile was analyzed according to Heirwegh et al. (2). Blood samples, $50 \mu$ l, were taken from the orbital sinus every 3 weeks during which these rats were under light ether anesthesia. Total serum bilirubin concentrations were determined according to the technique of Evelyn and Malloy (6).

\section{RESULTS}

Table 1 presents serum total bilirubin concentrations which were determined every 3 weeks after the grafting procedure. Serum total bilirubin concentrations of recipient rats were not significantly lower (Student's $t$-test) than those of sham-operated rats.

Liver microsomal suspensions from recipient and sham-operated rats lacked UDPGT (bilirubin) or UDP glycosyl transferase (bilirubin) activities. Microsomal suspensions from control Wistar rats prepared by the same procedure had both enzyme activities (Table 2).

Thin layer chromatography of azo pigments from bile of recipient and sham-operated rats showed $\alpha_{0}, \alpha_{2}$, and $\beta_{2}$ bands, but no $\gamma$ band (glucuronide-containing band).

The transplantation site in recipient livers was recognized by light microscopy as a cleft between the liver lobes which was probably caused by necrosis of transplanted tissue. The transplantation site contained macrophages laden with bile pigments, plasma cells intermixed with connective tissue, newly formed capillaries, and structures resembling bile ductules. In most animals, there was a reactive inflammatory granuloma in the area adjacent to the transplantation site. In one sham-operated rat which received liver biopsies from another Gunn rat, the transplantation site contained proliferated bile ducts with small islands of hepatocytes and macrophages intermixed with lymphocytes. 
After the grafting procedure, all rats remained healthy and gained weight.

\section{DISCUSSION}

Transplantation of normal rat liver into Gunn rat liver was associated with a decrease in total serum bilirubin concentration (Table 1). This is probably due to factors other than the grafting of Wistar rat liver tissue, because the serum bilirubin concentrations similarly decreased in sham-operated rats as well.

Histologic examination revealed that the grafted tissue disappears, as reported by Mukherjee and Krasner (3); however, UDPGT activity (bilirubin), UDPG glucosyl transferase activity (bilirubin), and bile analysis failed to reveal evidence of bilirubin glucuronide or bilirubin glucoside formation.

The operative techniques were identical. The total amount of grafted liver tissue was $180-250 \mathrm{mg}$ whereas, in the earlier study (3), transplanted plugs of liver tissue weighed 200-250 mg.

\section{SUMMARY}

Grafting of liver from normal Wistar rats into the liver of homozygous Gunn rats did not result in hepatic UDPGT activity in recipient rats or in the presence of bilirubin glucuronide in their bile.

1. Gunn, C. H.: Hereditary acholuric jaundice. J. Hered., 29: 137 (1938).

2. Heirwegh, K. P. M., Van Hees, G. P., Leroy, P., Van Roy, F. P., and Jansen, F. $\mathrm{H}$.: Heterogeneity of bile pigment conjugates as revealed by chromatography of their ethyl anthranilate azo pigments. Biochem. J., 120:877 (1970).

3. Jansen, P. L. M., and Henderson, P. T.: Influence of phenobarbital treatment on $p$-nitrophenol and bilirubin glucuronidation in Wistar rat, Gunn rat and cat. Biochem. Pharmacol, 21: 2457 (1972).

4. Jansen, P. L. M., and Arias, I. M.: Delipidation and reactivation of UDP glucuronyltransferase from rat liver. Biochim. Biophys. Acta, 391: 28 (1975).

5. Lowry, O. H., Rosebrough, N. J., Farr, A. L., and Randall, R. J.: Protein measurement with the Folin phenol reagent. J. Biol. Chem., 193: 265 (1951).

6. Malloy, H. T and Evelyn, K. A. The determination of bilirubin with the photoelectric colorimeter. J. Biol. Chem., 119: 481 (1937).

7. Mukherjee, B., and Krasner, J.: Induction of an enzyme in genetically deficien rats after grafting of normal liver. Science, 182: 68 (1973).

8. Van Roy, F., and Heirwegh, K. P. M.: Determination of bilirubin glucuronidation and assay of glucuronyltransferase with bilirubin as acceptor. Biochem. J., 107: 507 (1973).

9. This research was supported by a grant from the Commonwealth Fund and Grants AM 2019, 16281, and 17702 from the National Institutes of Health.

10. Requests for reprints should be addressed to: 1. M. Arias, M.D., Liver Research Center, Albert Einstein College of Medicine, 1300 Morris Park Ave., New York, N. Y. 10461 (USA).

11. Accepted for publication May 4, 1976.

\title{
Metabolic and Hormonal Responses to a Protein-Glucose Meal in Normal Infants and in Marasmus and Marasmic Kwashiorkor
}

\author{
GEORGE G. GRAHAM, ${ }^{(53)}$ JULIO NAKASHIMA, ROBERT G. THOMPSON, AND ROBERT M. \\ BLIZZARD \\ Instituto de Investigacion Nutricional, Miraflores, Lima, Peru and Department of Pediatrics, School of Medicine,
}

The Johns Hopkins University, Baltimore, Maryland, USA

\section{Extract}

Blood sugar and plasma free fatty acids $($ FFA), immunoreactive insulin (IR I), and growth hormone $(\mathrm{GH})$ responses to a protein-glucose meal were determined in normal infants and those with marasmus and marasmic kwashiorkor. Among the normal subjects, fasting blood sugar (BS), peak BS and IRI, and the IRI/BS ratio tended to decrease as age increased. Peak IRI was at least $13 \mu \mathrm{U} /$ $\mathrm{ml}$ above fasting in 21 of 24 infants. Fasting GH levels were high, $38.5 \pm 13.6$ (SD) and $26.3 \pm 14.0 \mathrm{ng} / \mathrm{ml}$, in the two youngest groups (under 1 year) and were comparable with those of the late newborn period. They were slightly lower, $20.8 \pm 22.1$, in those 12.5-18.5 months of age. Suppressions of FFA and subsequent rebounds were in close temporal relation to $B S$ and IRI peaks and lows, but not the GH levels. GH was promptly suppressed by the meal, and in most infants secondary elevations were seen.

Untreated marasmic infants had normal or low BS, correspond- ingly normal or low IRI, markedly elevated FFA $(1,821 \pm 588$ $\mu \mathrm{Eq} /$ liter), and GH levels comparable with those of the control subjects. There was some delay in BS elevation and disappearance and poor insulin release after the meal, with only two of nine having elevations of at least $13 \mu \mathrm{U} / \mathrm{ml}$. The BS elevations and IRI responses, however, were adequate to block $F F A$ release. GH levels were poorly suppressed by the meal but some infants had further elevations, possibly in response to protein. After partial rehabilitation, fasting BS and FFA and BS elevations after the meal were normal. A slight improvement in insulin release was apparent. Fasting GH levels and responses to the meal were normal.

Fasting, minimally treated children with marasmic kwashiorkor (MK) had normal or low BS, normal or low IRI, normal FFA, and probably normal GH levels. There was considerable delay in BS elevation, moderately delayed glucose disappearance, and very poor or unmeasurable insulin release after the test meal; FFA and GH were poorly suppressed. After partial rehabilitation, fasting BS was 